6. 1558 , abril 23. Valencia

Nombramiento de procurador

Archivo del Real Colegio del Corpus Christi de Valencia. Protocolos Notariales de Andrés Martín Pineda, n. ${ }^{\circ} 16.160$

Iam dictus die et anno.

Ego Maria Anna Boera, virgo, filia honorabili Petri Boera, quondam, mercatoris, civitatis Valencie habitatori, scienter et gratis, cum hoc presenti publico procurationis instrumento, facio, constituo et solemniter ordino procuratorem meum, certum et specialem, et ad in (...) penitus generalem. Ita tamen quod vos magnificum Hieronimum (...) camerarium, // comitis de Albayda licet, absentem tamquam presentem, videlicet ad nomine meo ed pro me petendum, habendum, accipiendum et recuperandum a quibusvis collegiis, personis, universitatibus et corporibus quascumque pensiones censualem mihi tam debitas quam debendas quovis nomine et titulo quam (...)que etiam ratione sive causa ubilibet et de hiis que habueritis, etc apocam vel apocas, albaranum vel albarana, finis, absolutiones, deffinitiones et alias quasvis cautelas convenientes et opportunas vobisque benevisas faciendum fierique faciendum, concedendum et firmandum, deposite et decetero, deponendo a quibusvis curiis, tabulis, taulegeriis et depositariis, levandum et recipiendum, ac (...) isse confitendum fida (...) iuris et (...) curie, dandum et offerendum (...) et (...)bona indemnes et indemnia servandum, promittendum sub bonorum omnium et iurium meorum obligatione et ad compacendum, etc. Fiat ad littes (...) posse substituendi, etc. Generaliter, etc. Promitto, etc. Sub bonorum // et iurium meorum omnium obligatione que ad cautelam cum presenti obligo. Quod est actum Valencie, etc.

Testes huius rei sunt honorabilis Hieronimus Cardona et Baptista Steve, pictores, Valencie habitatores.

\title{
EL TRONO EPISCOPAL DE LA CATEDRAL DE PALENCIA. UN ANTECEDENTE DE LOS PROGRAMAS TIPOLÓGICOS EN LAS SILLERÍAS CORALES GÓTICAS
}

Las sillerías de coro góticas con decoración figurada presentan a menudo un programa iconográfico basado en las relaciones tipológicas entre Antiguo y Nuevo Testamento que refleja de una manera muy sutil las aspiraciones y deseos de la institución eclesiástica coetánea. Este programa iconográfico tiene en su base el llamado «Doble Credo», que establecía conexiones diversas entre apóstoles y profetas ${ }^{1}$.

El tema tiene un origen muy antiguo, al menos por lo que respecta al credo apostólico ${ }^{2}$. La tradición dice que fue creado el día de Pentecostés, cuando los apóstoles aportaron cada uno una frase al texto del Credo, como un resumen doctrinal básico que cada uno de ellos utilizaría en sus predicaciones por las diversas partes del mundo. Como tal aparece, en la forma que será utilizado durante todo el período medieval, en los primeros tiempos del cristianismo, con diversas redacciones y asignaciones de textos a los apóstoles.

Desde el siglo xII el Credo de los apóstoles aparece relacionado con el Credo de los profetas, constituyéndose lo que se denomina comúnmente «Doble credo». De este modo a cada frase atribuida a un apóstol se le contrapone otra de las contenidas en cada uno de los libros proféticos, generalmente relacionadas entre sí y con el objetivo de ver en la segunda un antecedente o anuncio del hecho al que se alude en la primera.

Programas iconográficos derivados de esta relación fueron ampliamente utilizados en obras de arte, sobre todo en el último período gótico.

Algunas características del tema como la clara división en dos grupos de las figuras representadas y la relación desigual entre ambas, con preeminencia de unas sobre las otras, supusieron un uso especialmente abundante del doble credo en las sillerías corales, que presentaban en su configuración estructural dos partes o niveles claramente diferenciados (la sillería alta

1 P. Lacroix y A. Renon, «Apôtres et Prophètes au Credo: un thème iconographique entre le rayonnement et l'oubli», Pensée, image et communication en Europe médiévale. A propos des stalles de Saint-Claude, Besançon, 1993, pp. 83-100. M. A. Franco Mata, «El "Doble Credo" en el arte medieval hispánico», Boletín del Museo Arqueológico Nacional, XIII (1995), pp. 119-136. 
y la baja), pero relacionados entre sí por las características propias de las personas a quienes estaban destinados sus estalos (canónigos en el primer caso, racioneros en el segundo).

La utilización del doble credo en amplios programas iconográficos materializados en las sillerías corales por medio de cuidadas tallas figuradas aparece en el ámbito centroeuropeo en el siglo $\mathrm{XV}^{3}$. En España se utiliza por primera vez, con un amplio despliegue de representaciones, en la sillería catedralicia leonesa, de la segunda mitad del xv, que constituye el modelo que seguirán muchos otros conjuntos ${ }^{4}$. En el caso español, a los apóstoles y profetas se unen santos y personajes veterotestamentarios de diversos tipos, para completar las representaciones figuradas en un número de estalos bastante elevado.

Sin embargo, antes de la constitución del modelo citado, que se extendía en representaciones figuradas aisladas por los dorsales de los estalos, algunas sillerías corales recogieron también el tema del doble credo y sus extensiones en programas más sencillos. Un ejemplo claro de esta utilización temprana aparece en el trono episcopal de la sillería catedralicia de Palencia.

La sillería coral palentina se realiza en el primer cuarto del siglo xv, ampliándose y trasladando su ubicación a principios del xvi. El conjunto sigue una tendencia anicónica muy propia de las sillerías españolas, con un número muy reducido de representaciones figuradas que, a excepción del trono, se limitan a algunos motivos profanos en los elementos secundarios.

Es en el estalo obispal donde se desarrolla el programa iconográfico religioso basado en el tema anteriormente citado. La silla, que es algo anterior al resto de la obra, se haría en el primer cuarto de siglo, ya que se sabe que en una fecha indeterminada entre 1415 y 1422 estaba ya terminada ${ }^{5}$.

El estalo obispal se encuentra actualmente integrado en el conjunto de la sillería, concretamente en el centro de su lado occidental que presenta, como la mayoría de las sillerías españolas, esta parte completamente cerrada y ocupada, en el interior, por los estalos destinados a las dignidades y al obispo (fig. 1). El estalo obispal, sin embargo, no fue concebido para el lugar que ahora ocupa, como puede apreciarse en diversos fallos técnicos de ensamblado producidos al integrarlo entre las demás sillas de una manera diferente a la originalmente prevista, así como en la ocultación de algunos elementos tallados que antes de la integración quedarían visibles y que, de hecho, forman parte importante del programa iconográfico religioso, como sucede con los relieves laterales externos. Se desconoce cuando se produjo dicha integración, aunque todo indica hacia la época del traslado como momento más probable.

La silla del obispo es un estalo alto y estrecho, coronado por un elevado pináculo decorado con cresterías góticas, motivos vegetales y ángeles tenantes en su base ${ }^{6}$, con una bóveda de crucería cuatripartita en el interior. La silla presenta la forma habitual en los estalos góticos, con laterales cerrados, decorados al exterior con escenas religiosas y lisos al interior, ornados con sendos pináculos en el frente, sin apoyamanos y rematados en un sencillo brazal semicircular. El

\footnotetext{
2 J. P. Bouhot, «L'Origine apostolique du Symbole au Moyen Age», Pensée, image et communication..., pp. 159-164.

${ }^{3}$ P. Lacroix y A. Renon, «Les stalles savoisiennes: une iconographie caractérisée», Stalles de la Savoie médiévale. Catálogo de la Exposición, Ginebra, 1991, pp. 39-48.

${ }^{4}$ M. D. Teijeira Pablos, La sillería de coro de la catedral de León y su influencia en las sillerías corales del gótico final, Tesis doctoral publicada en edición electrónica, León, 1997. Id., Las sillerías de coro en la escultura tardogótica española. El grupo leonés, León, 1999.

${ }^{5}$ En la conocida carta que el cabildo envió a don Sancho de Rojas, que fue obispo de Palencia entre 1403 y 1415 y posteriormente arzobispo de Toledo hasta su muerte en 1422, demandándole una cierta cantidad de dinero para terminar la obra de la sillería, se dice expresamente que «... las sillas del coro de esta iglesia que vuestra señoría mandó hacer están en buen estado y serán acabadas en breve... Y la silla principal obispal está acabada, en la cual por vuestro servicio hicimos poner cuatro escudos en campo dorado con sus estrellas». La carta, hoy perdida, fue recogida por A. Fernández de Madrid, Silva palentina, Ed. de Palencia, 1976, p. 275.

${ }^{6}$ Ibidem. De los «cuatro escudos en campo dorado con sus estrellas» que se pusieron en la silla episcopal conserva uno el ángel tenante del lado izquierdo. El ángel de la derecha también se mantiene, pero ha perdido el escudo.
} 

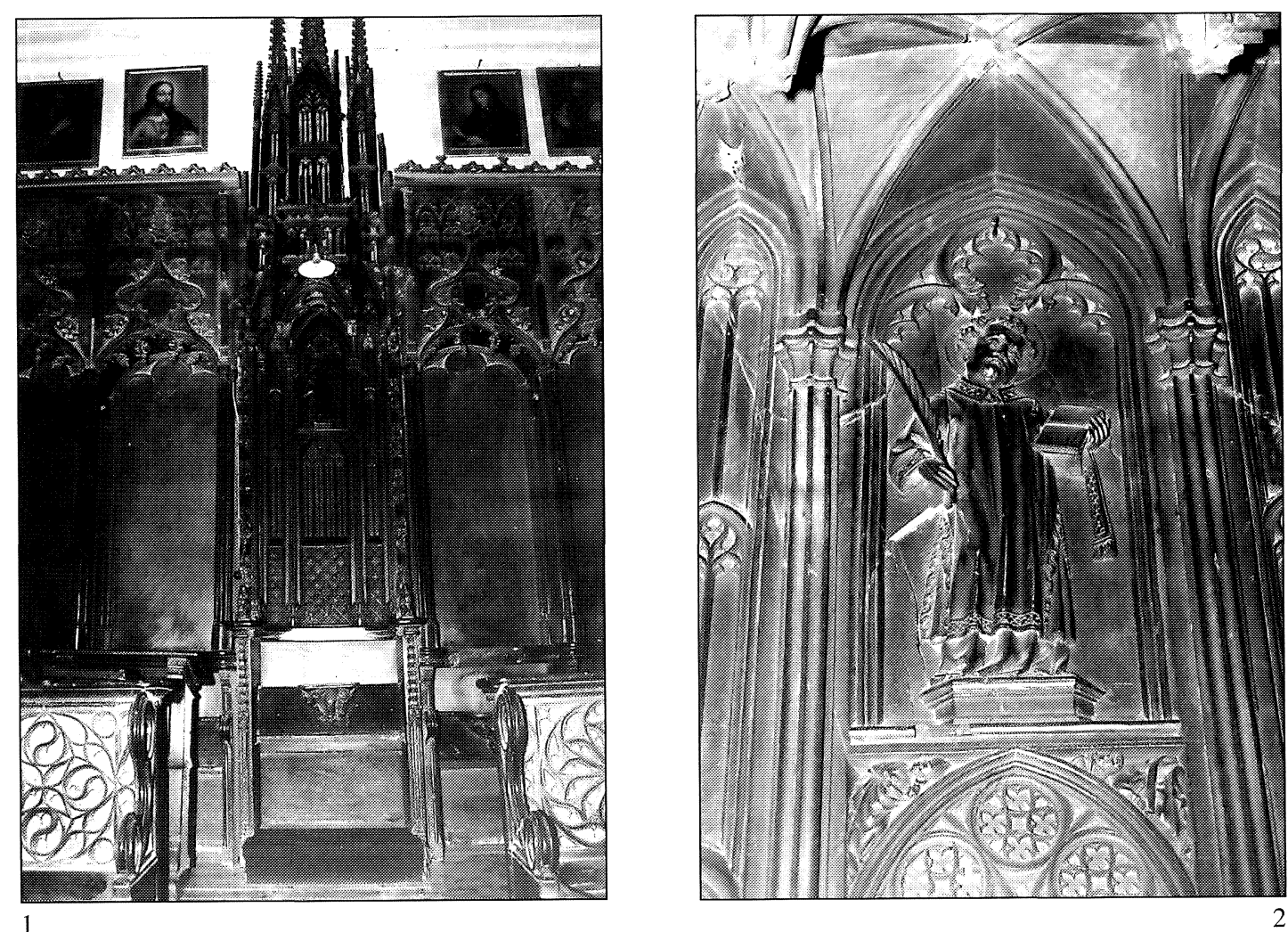

1

3

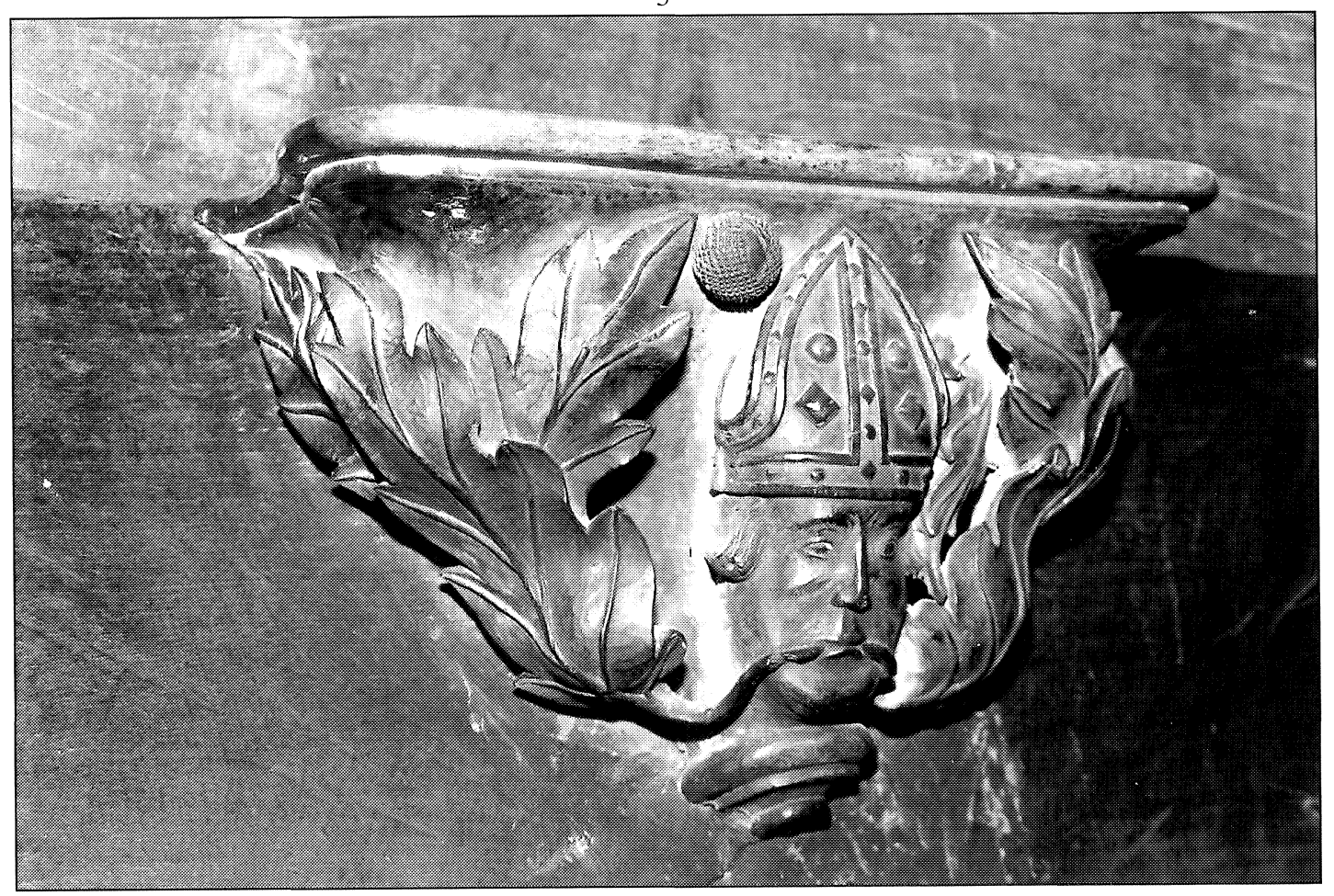

Fig. 1. Trono obispal de la sillería de la catedral de Palencia.

Fig. 2. Dorsal. San Antolín.

Fig. 3. Misericordia. Cabeza de obispo. 
asiento es giratorio, formado por un tablero rectangular que en su parte interior presenta una misericordia de simple trazado recto, decorada con la cabeza de un obispo (fig. 3). El dorsal consta de un tablero decorado con varios paneles rectangulares ornados con una red de rombos con cuadrifolias inscritas, combinados con motivos inspirados en las ventanas góticas, con un obispo y un profeta en las enjutas del elemento central, y rematados por una representación de San Antolín (fig. 2). Al tratarse de una silla hecha para colocarse exenta, el respaldo aparece flanqueado a ambos lados por sendas crosas caladas que lo protegen lateralmente y que son utilizadas como soporte iconográfico (fig. 4). Ambos elementos, desarrollados sobre sendos lados del brazal, presentan una estructura muy similar, en tres pisos ocupados por varias figuras de santos cobijadas bajo arco ojival y colocadas en pie orientadas hacia el exterior de la silla. En el remate frontal de ambos elementos aparecen, sobre pequeñas ménsulas, varias figuras de apóstoles, profetas y santos, en concreto veinte personajes distribuidos en cinco alturas en cada una de las cuales aparece una pareja. La parte inferior, en el extremo del brazal, presenta dos figuras sedentes, un profeta a la izquierda y un apóstol a la derecha. Finalmente, y aunque el programa iconográfico que se desarrolla en el trono obispal es íntegramente religioso, puede observarse un pequeño motivo marginal que viene a suplir la carencia de elementos profanos que habitualmente se desarrollan en algunos elementos de las sillerías, como la misericordia; en este caso aparece, tallado tras el profeta que se sienta sobre el extremo izquierdo del brazal, una pluma en su funda y un tintero, unidos por un cordón y colgados de un clavo.

En los elementos anteriormente descritos se desarrollan una serie de representaciones figuradas de diversos tipos en forma de escenas y figuras, solas o relacionadas unas con otras.

Las escenas aparecen en los paneles laterales que cierran la parte inferior de la silla, conformando el asiento. Este elemento que en el resto de estalos, al estar unos unidos a los otros, no deja apenas espacio para el desarrollo iconográfico, en este caso, al tratarse de un estalo exento, consigue dos grandes superficies cuadrangulares regulares aptas para el desarrollo de escenas más o menos amplias. La actual ubicación de la silla obispal, integrada en el lado occidental de la sillería, entre dos estalos del conjunto, oculta a la vista dichas escenas, por lo que sólo puede darse una idea aproximada de la composición de éstas. En el panel de la izquierda se representa la Anunciación de la Virgen bajo un arco, probablemente ojival, cuyo trasdós se decora con motivos vegetales. A la derecha de la composición aparece la Virgen, en pie y mirando hacia su derecha, donde se encuentra el arcángel, arrodillado ante ella. En el panel de la derecha se desarrolla en relieve la escena de la Resurrección de Cristo, con éste en el centro, sobre el sepulcro en uno de cuyos extremos aparece, dormido, un soldado. Esta segunda representación parece ser más sencilla en su composición, en parte debido a que puede extenderse únicamente por una parte del panel, ya que la inferior, lisa, está separada de la superior, donde se desarrolla la escena, por una línea curvada, que parece indicar, en esta parte, la existencia de un asiento giratorio, lo que supondría que en origen el estalo obispal habría estado no completamente exento, sino adosado por su lado izquierdo a uno de los extremos del conjunto coral, en concreto remataría éste por el lado septentrional.

Las figuras aparecen decorando el resto de los elementos del estalo, como ya se ha comentado. Algunas no aparecen completas, como sucede con la misericordia, decorada con una cabeza humana mitrada de cuya boca salen unos tallos vegetales cuyas hojas se extienden hacia los extremos (fig. 3); el resto, sin embargo, presenta figuras enteras bien en relieve, bien en bulto redondo. Entre las primeras la más destacada es la que corona el dorsal (fig. 2). Se trata de San Antolín, patrón de la ciudad y advocación principal de la catedral, representado como un diácono con palma, manípulo y libro, nimbado y colocado en pie, en posición frontal sobre una base colocada en la parte superior del respaldo. Éste presenta una composición a medio camino entre las tradicionales sillerías góticas de inspiración mudéjar, que decoran los paneles 
del dorsal con motivos geométricos, y las tardogóticas que los aprovechan para componer un complejo programa iconográfico religioso a base de figuras sagradas. En este sentido el trono palentino actuaría como nexo de unión entre dos tradiciones muy diferentes, marcando la transición de una tipología puramente medieval a otra que se desarrollará ampliamente en época moderna. La figuración relivaria del respaldo se completa con los personajes que aparecen en las enjutas del motivo en arco que decora el centro del dorsal, donde aparecen las figuras anteriormente mencionadas de un obispo, a la izquierda, y un profeta, a la derecha. Ambos son identificables por sencillos atributos como la mitra en el primer caso y el gorro picudo y la filacteria en el segundo, representándose el primero de ellos dormido sobre su mano izquierda y el segundo tumbado, probablemente como única forma de justificar la extraña postura consecuencia de la adaptación al espacio triangular de la enjuta.

Las figuras de bulto redondo se extienden por las crosas que rematan lateralmente la parte superior de la silla (fig. 4). Sobre los extremos del brazal aparecen sentados un profeta a la izquierda, cubierta la cabeza por un manto y sujetando sobre la rodilla una filacteria, y un apóstol a la derecha, con la cabeza descubierta y leyendo un libro que sujeta entre sus manos (figs. 5 y 6). En las crosas propiamente dichas aparecen las figuras más completas, en pie sobre una simple ménsula; en la izquierda, de abajo arriba, se ve a San Juan Bautista, sosteniendo el cordero, Santa Catalina (fig. 7), sobre la figura dormida del emperador, con un libro abierto y en la mano derecha probablemente la espada, hoy perdida y el arcángel San Miguel, alanceando al demonio que pica con una lanza hoy desaparecida. En la derecha San Antón, acompañado de un cerdo, una santa cuyo atributo ha desaparecido y un diácono hoy difícil de identificar al tapar este lado el coronamiento de la silla adyacente. Junto a ellas aparecen las pequeñas figuras de las columnillas de remate, entre las que se distinguen diez apóstoles — San Andrés, San Pablo, Santiago Alfeo, Santiago Zebedeo, San Mateo, San Pedro, San Simón, San Judas Tadeo, San Juan Evangelista y Santo Tomás-, cinco profetas y cinco santas — dos de ellas identificables por sus atributos, Santa Águeda y Santa Apolonia- (fig. 6). Estas veinte figuras presentan tres grupos de número desigual y por lo tanto desequilibrados, en los que la distribución por parejas es, consecuentemente, arbitraria: profeta-apóstol, profeta-profeta, apóstolapóstol, santa-profeta, santa-santa, santa-apóstol.

Los motivos así descritos forman, en el trono episcopal, un programa iconográfico de fuerte carga religiosa, similar a la de otros conjuntos posteriores, como los del grupo leonés ${ }^{7}$, pero con la importante diferencia de que mientras en los últimos se utiliza la mayor parte del conjunto como soporte iconográfico, en el caso palentino, al tratarse de una sillería anicónica, el programa se concentra en el trono episcopal.

Dicho programa parte de la relación profeta-apóstol, entendida ésta como una contraposición entre temas vetero y neotestamentarios, actuando los primeros como prefiguras de los segundos, en el sentido de que sus profecías se verían cumplidas en los textos que habitualmente se atribuyen a los apóstoles. Se trata, pues, del antiguo tema del «Doble Credo» que tanta importancia tendrá en los programas iconográficos desarrollados en las sillerías corales. De este modo un apóstol y un profeta aparecen sobre los extremos de los brazales, en una de las partes más visibles del estalo, como síntesis del programa. Ambos sentados, posición honorífica $^{8}$, y en pie de igualdad, manifestando la importancia de ambos grupos (figs. 5 y 6). Del mismo modo aparecen apóstoles y profetas en las columnillas de remate de las crosas, en parejas, aunque en muy pocas ocasiones se mantiene la disposición habitual apóstol-profeta, de-

\footnotetext{
${ }^{7}$ M. D. Teijeira Pablos, «Les stalles du groupe de León. Typologie et programme iconographique dans la sculpture gothique tardive espagnole», Révue de l'Art, 114 (1996) pp. 57-62.

${ }^{8}$ C. Charles, «Prophètes assis dans les stalles, un motif international au xv siècle», The Profane Arts of the Middle Ages, V, 1 (1996), pp. 46-88.
} 

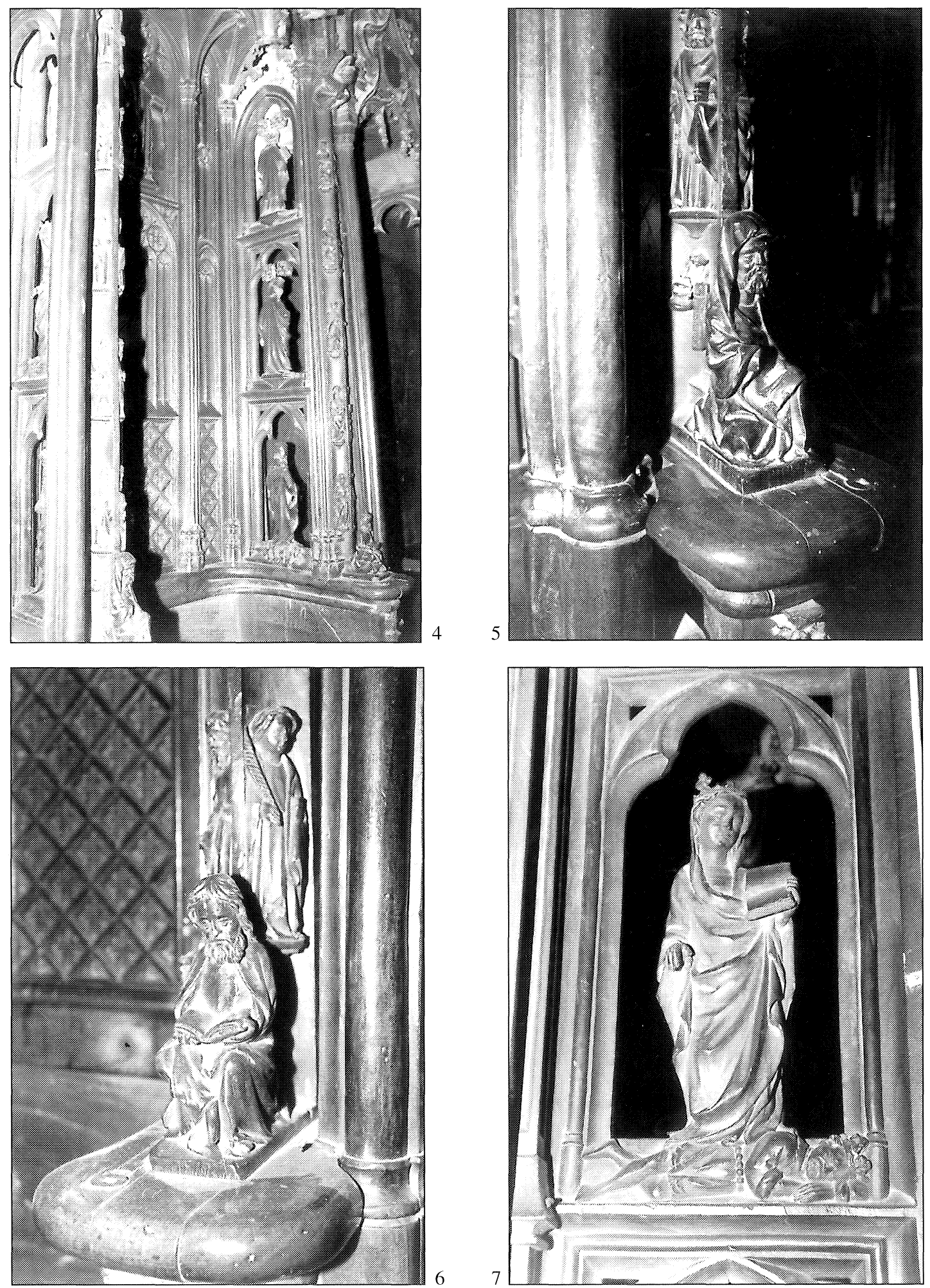

Fig. 4. Crosas

Fig. 5. Remate del brazal. Profeta.

Fig. 6. Remate del brazal. Apóstol.

Fig. 7. Crosa. Santa Catalina. 
bido en gran parte a la desigualdad del número de miembros de cada grupo, diez apóstoles y sólo cinco profetas. Además, los primeros van identificados por sus atributos habituales, mientras que los segundos suelen repetir un mismo modelo compositivo, por lo que la identificación de las diferentes figuras se hace imposible (fig. 6).

La base iconográfica del programa, la relación apóstol-profeta, se completa con la adición de otras figuras que matizan el mismo, dándole un sentido peculiar al mensaje que transmite la obra, como suele suceder también en otros conjuntos corales españoles. Las figuras de santos tienen, evidentemente, una relevancia especialmente destacable, no sólo por su variedad o la magnitud de sus dimensiones, sino también por ocupar los soportes principales dentro de la estructura del estalo. Se trata, además, de figuras especialmente escogidas en representación de los diferentes grupos de santos que componen las bases fundamentales de la institución eclesiástica: San Juan Bautista como último profeta, nexo pues de unión entre Antiguo y Nuevo Testamento, San Antón como representante de la vía monástica, San Miguel de los ángeles, las santas de los mártires o el diácono de los miembros de la Iglesia. El tono local lo pone San Antolín, en alusión directa a la propia institución catedralicia. De este modo se consigue, con un número de figuras limitado, un amplio despliegue de personajes que resumen en sí mismos los pilares sobre los que se apoya la iglesia coetánea, sin faltar ella misma representada en la figura obispal repetida en la misericordia y en la pequeña enjuta del dorsal, en este caso junto al profeta, en sustitución del apóstol de quien el primero sería heredero directo. Sin embargo, el obispo, y por extensión los miembros de la iglesia, no están al mismo nivel que los apóstoles y los santos cuya labor continúan y, por lo tanto, el programa iconográfico respeta la jerarquía reservando estas representaciones para zonas del estalo consideradas habitualmente de importancia secundaria y que, en otras ocasiones, se decorarían con temas profanos.

Llama la atención el número de santas utilizado en esta obra. Habitualmente, en sillerías corales con programas iconográficos del mismo tipo, a las santas suele otorgárseles un papel un tanto secundario, al representarse en los últimos estalos, dando mayor relieve a los santos masculinos. Sin embargo, en el caso palentino el número de santos es mucho menor que el de santas, que por contra aparecen en representaciones menos individualizadas, como si se tratase de figuras de relleno, que vienen a cubrir un hueco en la estructura sin tener un peso específico importante. Esto es especialmente visible en las imágenes de las columnillas de remate donde, por otra parte, la selección de figuras y su modo de relacionarlas unas con otras parecen haber sido fruto más de la casualidad que de una intención expresa de utilizarlas con un determinado sentido en el programa iconográfico, lo que puede interpretarse, quizá, como señal de la mala comprensión o del desconocimiento de las implicaciones del programa utilizado o de un error en la adaptación del programa a una estructura para la que habitualmente no se usa y en un momento en el que no había aún un modelo iconográfico bien definido.

A todo esto habría que añadirle el complemento de las escenas anteriormente descritas, que supondrían la alusión directa al dogma de la redención a través de dos momentos especialmente representativos, la Anunciación como inicio y la Resurrección como culminación, introduciendo de este modo las figuras de Cristo y la Virgen que, a pesar de su importancia, no suelen tener un papel especialmente significativo en este tipo de programas.

Finalmente, el pequeño motivo marginal anteriormente citado, la pluma y el tintero, más que un simple motivo decorativo podría interpretarse como un elemento de refuerzo del sentido general del programa, en alusión a la importancia del texto escrito, el Antiguo y el Nuevo Testamento, como base del dogma cristiano.

El uso de este programa, muy frecuente en obras de la segunda mitad del siglo, especialmente de sus últimos años, en una obra tan temprana como ésta puede ser la causa directa de los fallos o desconexiones detectados, aunque sí parece que su núcleo fundamental se entendió 
a la perfección y se aplicó de una manera muy sutil, con pequeñas alusiones de matiz que, aunque pueden pasar desapercibidas, seguramente tuvieron para los iconógrafos una importancia muy grande. De este modo, la utilización de las figuras del obispo junto con las de los apóstoles, profetas y santos pero sin confundirse en ningún momento con ellas, parece querer dirigir el sentido original del programa - un despliegue, en clave triunfal, de figuras religiosas que marcan la evolución entre la profecía judaica y su cumplimiento en la obra de Redención, que aquí aparece representada en las escenas de los laterales- hacia la situación de la institución eclesiástica en los años en que se realizó la obra.

En esta época, el primer cuarto del siglo xv, la Iglesia está viviendo uno de sus períodos más críticos, tanto a nivel general como local. En primer lugar se está liquidando el cisma que había mantenido dividida a la Iglesia durante un período de tiempo bastante largo, con la abdicación de Gregorio XII y Juan XXIII y la deposición, en 1417, de Benedicto XIII en el concilio de Constanza, donde se intentó hacer una reforma profunda en la estructura de la iglesia por parte de algunas naciones europeas con el emperador a la cabeza, reforma interna que paralizarían precisamente los votos de la delegación castellana, formada entre otros por el deán de la catedral palentina, Diego Fernández de Valladolid ${ }^{9}$. Hay que recordar que Castilla fue en todo momento el apoyo principal del papa Benedicto, defensor del mantenimiento de la autoridad absoluta del Papa contra el galicanismo preconizado por algunos monarcas, y que en la lucha por mantenerlo en el papado participó de una manera muy activa Sancho de Rojas, quien impulsó decididamente la construcción de la sillería palentina y cuyo escudo puede todavía verse en el trono episcopal. El deseo papal, compartido por el rey y otros altos castellanos, especialmente los eclesiásticos, de que el poder civil del emperador y de los diferentes reyes europeos no se inmiscuyera en los asuntos internos de la Iglesia, paralizando de este modo los intentos de reforma interna que estaban ya siendo demandados desde diferentes zonas de Centroeuropa, puede verse plasmado en el programa iconográfico que se desarrolla en el trono palentino. En segundo lugar el reino castellano, y en concreto la ciudad de Palencia, habían vivido hechos históricos de enorme importancia que ponían de manifiesto la crisis de la institución eclesiástica y sus no siempre buenas relaciones con el cada vez más importante poder civil. La necesaria reforma moral de la iglesia castellana, tan debatida durante todo el siglo XIV, se plasmaría, aunque sólo sobre el papel, en las constituciones promulgadas en 1388 por el Concilio nacional celebrado en Palencia durante la reunión de Cortes y presidido por el cardenal Pedro de Luna, futuro papa Benedicto XIII. Por otra parte, el creciente poder del monarca castellano y la debilidad de la iglesia servirían de base a Enrique III y a otros monarcas castellanos para sustraerse a la obediencia al Papa entre 1398 y 1403, una muestra significativa de la relevancia que al poder civil iba adquiriendo en los asuntos de la Iglesia.

La enorme importancia de estos sucesos y su posible trascendencia no pasaron desapercibidos para la institución eclesiástica, seriamente amenazada por sus propios problemas internos, así como por la presencia, en su entorno inmediato, de otras fuerzas emergentes que intentarán acaparar parcelas de poder anteriormente controladas por la propia Iglesia. La utilización de determinados programas iconográficos en las obras religiosas supondrá, a menudo, un intento de reivindicar el papel que tradicionalmente había desempeñado la institución y cuya pérdida paulatina se achacaba, en parte, a la grave situación de debilidad del propio organismo. Por esta razón los programas como el desarrollado en el trono de Palencia se dirigirán muy directamente a los propios religiosos, recordándoles sus deberes como tales y la necesidad de mantener la organización jerárquica tradicional, ejemplificada en la división en grupos de diferente nivel e importancia de las figuras religiosas representadas y en la relación

${ }^{9}$ L. Suárez Fernández, Castilla, el cisma y la crisis conciliar (1378-1440), Madrid, 1960. 
prefigurativa que las unía. No hay que olvidar, en este sentido, que dicho programa se desarrolla en el trono obispal, evitándose en el resto de los estalos toda referencia iconográfica al ámbito sagrado, una forma más de destacar la importancia de la «cabeza» eclesiástica, en este caso local —el obispo- sobre los «miembros» - los canónigos que componían el cabildo y los racioneros que completaban el coro-.

\section{María Dolores Teijeira Pablos Universidad de León}

\section{DE CASTELLÓN A ROMA: EL CANÓNIGO VICENTE GINER (Ca. 1636-1681)*}

La presencia de un artista español en la Roma papal, se contempla siempre como un privilegio de disfrute infrecuente, en los siglos del Renacimiento y el Barroco. No es hasta el pleno siglo XVIII, con la institucionalización de los pensionados de San Fernando, cuando la constancia documental de los españoles en las academias romanas parece hacerla más habitual.

Limitadísimas son las noticias que disponemos de ellos, casi siempre procedentes de crónicas y raramente de documentos exhumados de los archivos romanos, lo que explica que la andadura italiana se haya tenido como excepcional. Ante la penuria de datos, parece arriesgado aventurar una «solución» concluyente sobre el tema de los españoles en Roma. Sobre todo, en una Roma en la que hay sobrados indicios de una colonia española de cierta importancia, dedicada a los oficios de la embajada, al comercio y, sobre todo, pululando alrededor de la poderosa curia vaticana. Como toda corte, Roma se llenaba de personajes ansiosos de medrar a la sombra del poder. Pero al tratarse de una corte clerical y universalista, proliferaron de antiguo los religiosos de todas las naciones europeas, prestos a ocupar puestos de cualquier índole en el escalafón. En este ambiente, quizá si se comprenda mejor la permanencia de un español en la Ciudad Eterna, que no la breve estancia que se le presupone a los artistas.

Artista y sacerdote, canónigo y pintor, aunque desconozcamos qué fue primero, Vicente Giner reúne ambos clichés que justifican su aparición en Roma, en los últimos años del siglo XVII. Aunque por ahora es un total desconocido. De su producción, apenas se han identificado con seguridad media docena de obras, y nada se sabe de su vida o de las fechas en las que ésta se desenvolvió. Debía ser persona con cierto ascendiente sobre sus colegas de pincel, cuando el único dato cierto sobre él hasta la fecha, es su liderato del malogrado intento de crear una Academia de artistas españoles en Roma, en $1680^{\prime}$. Afortunadamente, hoy disponemos de nuevos rastros documentales de la presencia de Giner en Italia, que informan de su procedencia y de su situación en el ambiente romano. Con ellos podemos hoy pergeñar en lo sustancial su personalidad en los últimos años de su vida.

\footnotetext{
${ }^{*}$ La labor de archivo que ha dado lugar a este trabajo, se ha realizado con cargo a una Beca Doctoral concedida por la Fundación Caja de Madrid. Quiero agradecer a Magdalena Lapuerta, Cristina Aragón, Felipe V. Garín y a la «bella ragazza» la ayuda y apoyo prestados durante mi estancia en Roma, haciendo posible este escrito.

${ }^{\prime}$ Conde de la Viñaza, Adiciones al Diccionario de los más Ilustres Profesores de las Bellas Artes en España, vol. II, Madrid, 1894, pp. 271-278. El documento original de la propuesta se encuentra protocolizado en el Archivio Storico Capitolino di Roma (ASC), Archivio Generale Urbano (AGU), sez. 10, prot. 642, s.f. (28-VII-1680). La copia consultada por Viñaza, acompañando la correspondencia del marqués del Carpio, se localiza en el Archivo General de Simancas (AGS), Secretaría de Estado, leg. 1156, carpeta 3063. Véase también Luis Pérez Bueno, «De la creación de una Academia de Arte en Roma. Año 1680 (1)», Archivo Español de Arte (AEA), 1947, pp. 155-157. Francisco J. Sánchez Cantón, «Nota acerca de la creación de una Academia de Arte en Roma. Año 1680», AEA, 1947, p. 255.
} 